\title{
Case \\ Report \\ Ductal adenocarcinoma of ventral surface of the tongue: An unusual presentation
}

\author{
Halli R, Kini R, Bither $\mathbf{S}^{1}$ \\ Department of Oral and Maxillofacial Surgery, Rural Dental College, Loni Bk - 413 736, Maharashtra, \\ ${ }^{1}$ Department of Oral and Maxillofacial Surgery, Christian Dental College, Ludhiana - 141 008, Punjab, \\ India.
}

Correspondence to: Dr. Saurab Bither, E-mail: saurabbither@yahoo.com

\begin{abstract}
There are very few cases reported of adenocarcinoma of the tongue. We report an unusual case of a 60-year-old female having a large, pedunculated ductal adenocarcinoma that had arisen from ventral surface of the tongue. The lesion was managed by surgery.
\end{abstract}

Key words: Ductal adenocarcinoma, pedunculated, ventral tongue

\section{Introduction}

In the literature on salivary gland tumors the term 'adenocarcinoma' is frequently used as a generic designation of a large group of neoplasms. ${ }^{[1]}$

Ductal adenocarcinoma is a slow growing malignancy occurring mainly in minor intra-oral salivary glands, particularly the palate. Following the criteria set out in, for example, the WHO blue book, it is usually fairly easy to recognize them by microscopy. ${ }^{[2,3]}$ The presentation of the lesion from the ventral surface of the tongue is a rare one and to our knowledge there has not been any previous report in the literature.

We present an unusual and rare presentation of ductal adenocarcinoma arising from the ventral surface of tongue. Another unusual thing is absence of palpable neck nodes.

\section{Case Report}

A 60-year-old female presented with a 45-day history of difficulty in swallowing and a seven-day history of difficulty in breathing and inability to speak properly. She gave a positive history of tobacco use and 'mishri' application.

Intraoral examination revealed a $6.5 \times 3.5 \times 4 \mathrm{~cm}$ pedunculated mass arising from the ventral surface of the tongue. The surface of the lesion was smooth and covered with normal mucosal texture [Figures 1, 3]. The lesion was firm and painless and had increased in size. It was resting over the dorsal surface of tongue, obstructing the oro-pharynx and the patient was not able to close her mouth completely.

Incisional biopsy was obtained from the lesion, which revealed it to be a ductal type of adenocarcinoma [Figure 2].

The lesion was excised from its base, under general anesthesia and primary closure achieved [Figures 4, 5]. At 16-month postoperatively the patient is symptom free [Figure 6].

\section{Histopathology}

$\mathrm{H}$ ematoxylin and eosin stained section revealed proliferating malignant ductal epithelial salivary cells. $M$ any cysts-like spaces containing large quantity of mucous and papillary in-growth are seen. At the periphery of the lesion the tumor cells are arranged in parallel arrays of elongated tubular forms. The tumor cells are surrounded by a connective tissue stroma.

The tumor cells have a deceptively uniform appearance. The cells can exhibit different growth patterns polymorphous; includes solid nests and trabeculae, tubules, papillae, cyst, cribriform or pseudoadenoid cystic 


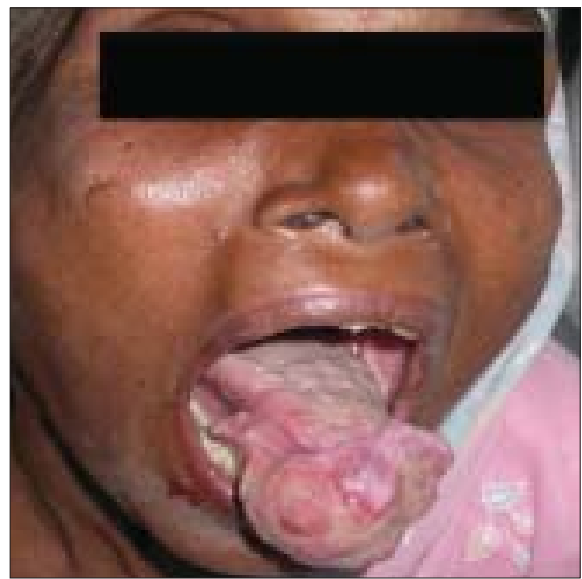

Figure 1: Gross appearance of the lesion

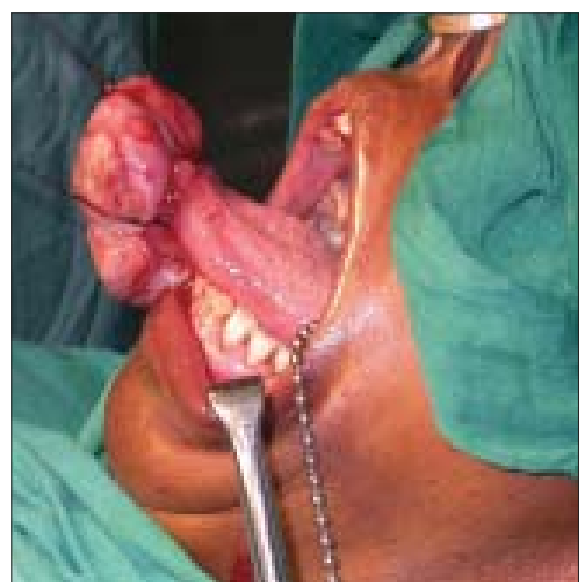

Figure 3: Gross appearance of the lesion

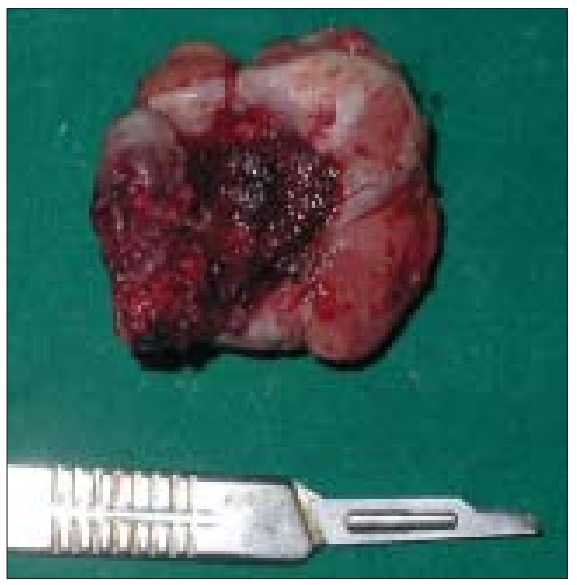

Figure 5: Excised specimen

formations, strands and fascicles. Combinations and transitions among these patterns are frequently seen.

\section{Discussion}

$\mathrm{H}$ istologically, ductal adenocarcinoma of minor salivary gland is characterized by its morphological variability,

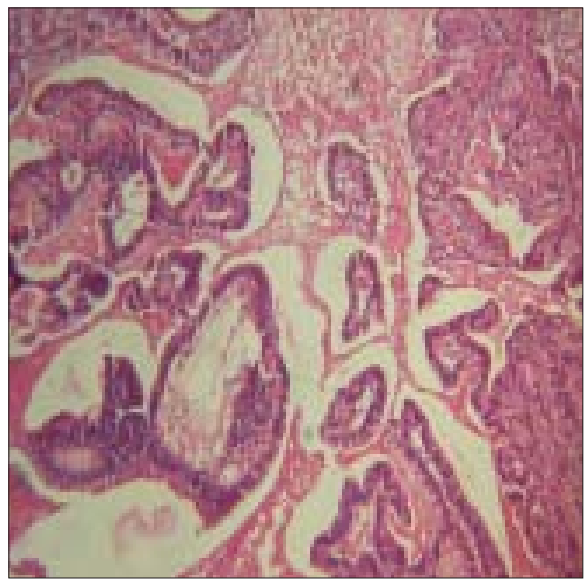

Figure 2: Haematoxylin and eosin stained section

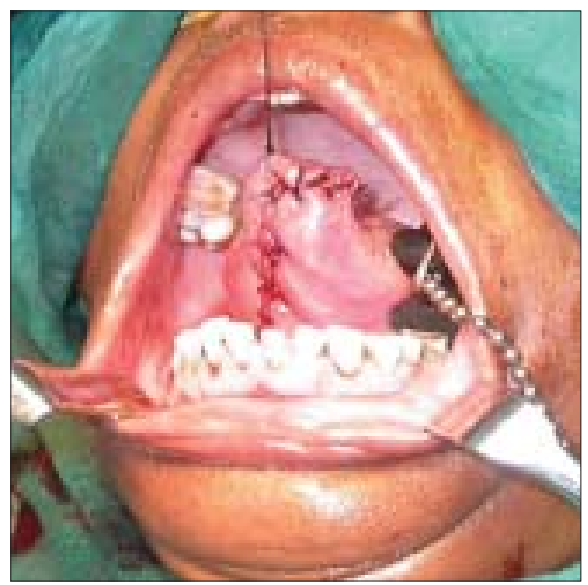

Figure 4: Primary closure

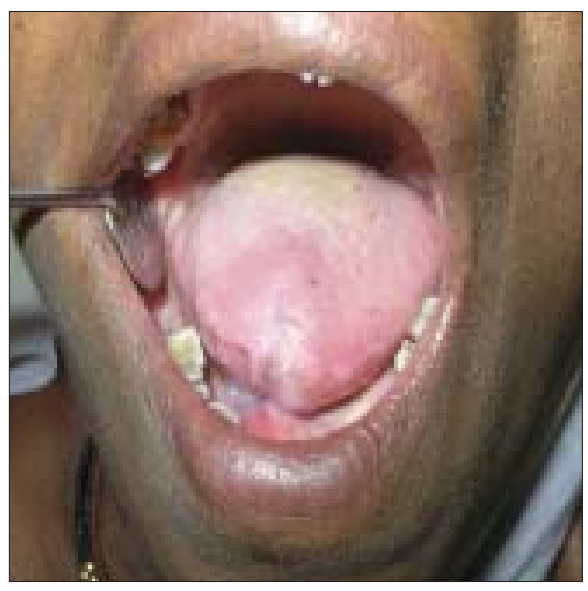

Figure 6: 16 month postoperative photograph

cytological baldness and an infiltrative growth pattern. ${ }^{[4]}$ WHO classification of head and neck tumors 2005 distinguishes it to be a separate entity. ${ }^{[5]}$ Tumors with a conspicuous papillary component are associated with higher incidence of lymph node metastasis and rarely ductal adenocarcinoma may undergo transformation to a high grade tumor. ${ }^{[6]}$ 
Differential diagnosis includes adenoid cystic carcinoma, monomorphic adenoma, pleomorphic adenoma and papillary cystadenocarcinoma. ${ }^{[4,6]}$

The ductal adenocarcinoma can metastasize to neck nodes, which require neck dissection along with surgical excision followed by radiotherapy. There has to be a long-term patient follow-ups as the mortality rate associated is high and prognosis is poor.

\section{References}

1. Evans HL, Batsakis JG. Polymorphous low-grade adenocarcinoma of minor salivary glands: A study of 14 cases of a distinctive neoplasm. Cancer 1984;53:935-42.
2. Seifert G, Sobin LH. Histological classification of salivary gland tumours. $2^{\text {nd }}$ ed. Berlin: Springer-Verlag; 1991.

3. Michal M, Skalova A, Simpson RH, Raslan WF, Curik R, Leivo I, et al. Cribriform adenocarcinoma of the tongue: A hitherto unrecognized type of adenocarcinoma characteristically occurring in the tongue. Histopathology 1999;35:495-501.

4. De Diego JL, Bernaldez R, Prim MP, Hardisson D. Polymorphous lowgrade adenocarcinoma of tongue. J Laryngol Otol 1996;10:700-3.

5. Barnes L, Eveson JW, Reichart P, Sidransky D. Pathology and genetics of head and neck tumours (World Health Organization classification of tumors). Vol. 9. France: IARC Press; 2005.

6. Rosai J. Oral cavity and oropharynx. In: Rosai and Ackerman's Surgical Pathology, 9th ed. Vol 1. Mosby Elsevier; 2004. p. 260-1.

Source of Support: Nil, Conflict of Interest: None declared. 